\title{
Preliminary Study on Geospatial Techniques to assess and enhance water Quality of Uttarakhand, India
}

\author{
Uniyal D. P. ${ }^{1}$ 凶, Aswal J. S., ${ }^{2}$ Bari K. S., ${ }^{2}$ Pokhriyal A., ${ }^{2}$ Dobhal R., ${ }^{2}$ Kaushik P. K., ${ }^{3}$ Sinha \\ V., ${ }^{3}$ Singh P. ${ }^{4}$ and Chander V. ${ }^{5}$
}

Received: 28.11 .2018

Revised: 25.03.2019

Accepted: 28.05.2019

\begin{abstract}
Uttarakhand being a mountainous state having maximum area under forest cover, about $65 \%$ and provides large amount of freshwater river for Ganga basin where habitation and agriculture are dominant. The rising demand of drinking water due to population growth also leads to the water scarcity in the terms of availability of quality drinking water. Contamination mentioned by Central Pollution Control Board (CPCB), 2009 and low per capita availability of quality drinking water reported by Department of Science and Technology (Government of India), 2010-2015, are the key issues of the state. To understand the availability of safe drinking water it is necessary to understand the overall hydrology of the basin in a spatial domain. The utilization of advance tools and techniques such as spatial models, geo statistical tools, high resolution remote sensing data and numerical hydrological model in the present study will enhance and ensure the water quality issue of Himalayan state of Uttarakhand which is expected to serve the society living along the river basin as well as in mountainous systems. The study will ensure the availability of sufficient quality drinking water to the communities in the selected watershed of each districts, considering the environmental aspects and human health while assessing 26 water quality parameters like color, odour,taste, turbidity, pH, total hardness, iron, chloride, chlorine, fluoride, total dissolved solids, calcium, magnesium, copper ,manganese, sulphate, nitrate, phenolic compound, arsenic, cadmium, lead, zinc, chromium, alkalinity and coliform bacteria etc. and also provide feasible solution of sustainable availability of water. Geospatial water quality and quantity model help to find out the spatio-temporal analysis of contamination and particles movement in the watersheds. Modern geo statistical simulation algorithms can produce multiple subsurface realizations that are in agreement with the conceptual geological models. The quality modeling and monitoring will help in providing portable surface and ground waters to the citizens.
\end{abstract}

Keywords: Hydrology, Water quality, Geospatial models

\section{Introduction}

Over exploitation of our water resources resulting in the use of poor quality and quantity of water for drinking especially in water stressed zones, which through food cycle enters in to human and animals, causing increased risk of various diseases as per as low per capita availability in rural and urban areas. Moreover, direct surface, subsurface and ground waters are still the main source of drinking water in rural areas and few cities of India. Over extraction and inadequate recharge is quite a common problem. Of course poor people have tended to suffer the greatest health burden from inadequate

\section{Author's Address}

${ }_{1,2 \& 5}$ Uttarakhand State Council for Science \& Technology, Vigyan Dham, Jhajra, Dehradun

${ }^{3}$ The Energy and Resources Institute University, New Delhi

${ }^{4}$ Dayananda Anglo Vedic (PG) College, Dehradun.

E-mail.: dpuniyal.ucost@gmail.com and poor quality water supplies (Chiang and Kinzelbach,1998) and as a result of poor health, have been unable to escape from the cycle of poverty and waterborne diseases. The key characteristic of the freshwater resources is their uneven distribution and variability with respect to time and space. The challenges being faced by water resource managers for any given location are a unique combination of mainly physical, cultural and engineering factors. It seems rationalized that effective mitigation measures are needed to cope up with climate change along with an adaptive strategy. Innovations in institutional arrangements and management structures are a necessary precondition for tackling the problems of management of supply of good quality and adequate quantity of water for its citizens. Waste 


\section{Uniyal et al.}

and inadequate management of water are the main culprits behind growing problems, particularly in poverty-ridden regions.

To understand the availability of safe drinking water it is necessary to understand the overall hydrology of the basin in a spatial domain (Brown and Matlock, 2011).With the rising demand of drinking water due to population growth leads to the water scarcity on terms of availability of safe drinking water. The magnitude of the water deficit must be returned into the system in order to sustain the balance between available water and water demand. Water resource supplies using the Water Stress Indicator recognizes environmental water requirements as an important parameter of available freshwater (Asheesh and Mohamed. 2003; Brown and Matlock, 2011). Over the years, rising population, growing industrialization and expanding agriculture have pushed up the demand for water. Water quality (Carr and Neary, 2010) decides the extent to which it can be used for the purpose. Thus, quality and quantity aspects of water need to be evaluated thoroughly to meet the ever increasing needs of water for different uses especially for drinking as well as agricultural uses. Uttarakhand provides large amount of fresh river water for major part of the Ganga basin where habitation and agriculture are dominant. Contamination mentioned (CPCB, 2009) by Central Pollution Control Board (CPCB) and low per capita water availability (DST, 2015) reported by Department of Science and Technology, Delhi is the two key issues of this state. Contamination of water resources has become a major threat to human security particularly in developing countries like India. In fact, water quality problems are caused by pollution and over-exploitation. Both human and natural activities can changes the physical, chemical, and biological characteristics of water and will have specific ramifications for health of humans and ecosystems. It is the need of the hour to understand surface and groundwater resource potential in respect to aquifers through Geospatial techniques. Geospatial water quality and quantity models help to find out the spatiotemporal analysis of contamination and particle movement in the watershed. Modern geo-statistical simulation algorithms can produce multiple subsurface realizations that are in agreement with conceptual geological models and statistical rock physics can be used to map these realizations into physical properties that are sensed by the geophysical or hydro-geological data (Linde et al., 2015). The quality modeling and monitoring help in providing potable surface and ground waters to the citizens, there should be comprehensive study of natural environment, human dimension and management practices under upstream downstream linkage. These linkages will be possible in a very effective manner if planning and action plan are based on geospatial environment. The geospatial environment will study the entire components of linkages with geographical coordinate location and their spatial association. This project is the extension of earlier projects funded by the Department of Science and Technology (Government of India), in which all 13 districts water quality primary data was generated. In the present study, under the project "Modelling for Enhancing Water Quality in Uttarakhand using Geospatial Technology" funded by the Department of Science and Technology (Government of India), the primary data in the previous projects and in the gap areas, may be incorporated in Remote Sensing and Geographical Information System platform to develop a model.

\section{Materials and Methods}

Present study was initiated in the month of July 2017 with an objective to create a Hydro-geo spatial model of Uttarakhand using geospatial tools and techniques to target hot spot zones and take a decision to resolve the problems of water quality in various districts in collaboration with Uttarakhand Council for Science and Technology, Dehradun.The. The Energy and Resources Institute, Delhi and Dayananda Anglo Vedic (PG) College, Dehradun.The. The present paper is hypothesis of study for improving drinking water quality and quantity by the utilization of remote sensing and geographical information system techniques. The primary data was already generated in all 13 districts viz; Dehradun, Haridwar, Pauri, Tehri, Chamoli, Uttarkashi, Rudraprayag, Nainital, Almora, Pithoragarh, Bageshwar, Champawat and Udham Singh Nagar under the project of water surveillance.

In the present study, Geo-spatial techniques and tools were selected for the modeling of water 


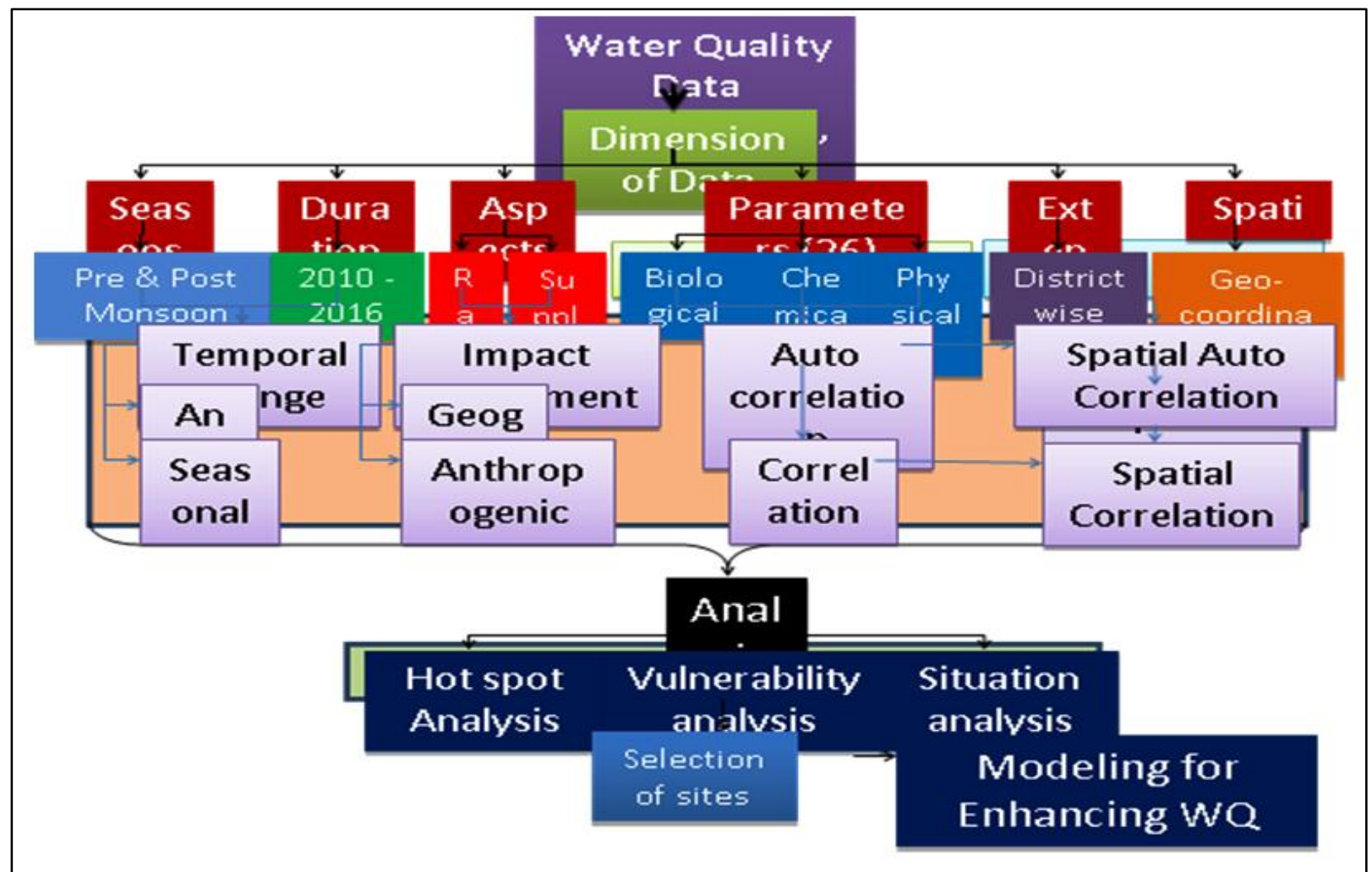

Fig.1 Method adopted to develop a hydro-geological model

quality in all 13 Districts of the state. The Geospatial techniques will centralized to target the hot spot zone and take a decision to resolve the problems of water quality stress in the Uttarakhand with Sustainability of environment. The parameters viz., Water quality assessment, Water quality index, Stress index, Social issues, Geo-statistical analysis of poor water quality, aquifer dynamics were selected for the development of water atlas of the Uttarakhand state. To study the water level at various hydro-geo morphological units of the watershed during pre-monsoon and post monsoon seasons, the water level indicator was selected to measure from the various open wells / tube wells using. It was also cleared in the present study, the samples will be collected based on stratified random sampling and number of sites selected based on area of micro watersheds.

It was also cleared in the approach and methodology of study that, the collected water samples will assessed to determine the water quality, its vulnerability index and stress index. GALDIT' methodology was selected to determine the Groundwater vulnerability index. In
GALDIT methodology, it is a ranking system, consists three main parts: weights, ranges and rating used to map the groundwater vulnerability index using GIS. Each GALDIT parameter has been assigned a relative weight ranging from 1 to 4 based on standardized method. Groundwater vulnerability index is computed by multiplying the value attributed to each parameter (rating) with its relative GALDIT weight and then adding all six products. Higher the GALDIT score more the aquifer is vulnerable (http://www.aprh).

G- Groundwater occurrence (aquifer type: unconfined, confined or leaky confined)

A- Aquifer hydraulic conductivity

L- Height of groundwater level above mean sea level

D- Distance from shore (distance inland, perpendicular from shoreline)

I- Impact of existing status of seawater intrusion in area

$\mathrm{T}$ - Thickness of aquifer being mapped

Groundwater Vulnerability Index $=1 \times \mathrm{G}+3 \times \mathrm{A}+$ $4 \times \mathrm{L}+2 \times \mathrm{D}+1 \times \mathrm{I}+2 \times \mathrm{T}$ 
Each sites of water quality will be tested through vulnerability index and will see how society is affected by their score. A detailed temporal dynamics of each quality parameters will be evaluated through geo-spatial model to find out the temporal change throughout in spatial distribution. This help to assess the causes and affect of each quality parameters in terms of pattern and dynamics. A depth field investigation survey was also selected out in different part of towns and surrounding rural area depending on the various water sources to determine the Social and economic response of people and different sectors in regard to poor water quality. The approaches were selected in this study will helpful to develop the sustainable spatial water to remove poor water quality availability in hilly areas especially in Himalayan state Uttarakhand.

\section{Results and Discussion}

A comprehensive understanding of water quality, as a key issue, will provide the knowledge and solution to society, water resource engineers, planners, environmentalist, agriculturist and academia essential in precision agriculture and drinking purpose. Modeling of natural drinking water resources of Uttarakhand through Geospatial techniques will provide a feasible solution of sustainable water availability in hilly terrain conditions of Himalayan region that amounts to sustainable practice of water retention in an urban and peri urban surroundings, rural background that manifests as watershed model, satellite data of high spatial resolution is required for image interpretation for various thematic layers LULC, soil map, geomorphology, geology, hydrogeomorphology and drainage mapping. This high spatial resolution data is used to prepare a geospatial model which will suggest decentralized inflow of water in the urban areas through various means like rainwater harvesting, perched water harvesting for urban and surrounding rural areas for long retention of water and long sustainable water cycle. To understand the availability of safe drinking water it is necessary to understand the overall hydrology of the basin in a spatial domain.

The utilization of advance tools and techniques such as spatial models, geo statistical tools, high resolution remote sensing data and numerical hydrological model in the present study will enhance and ensure the water quality issue of Himalayan state of Uttarakhand which is expected to serve the society living along the river basin as well as in mountainous systems. The study will ensure the availability of sufficient quality drinking water to the communities in the selected watershed of each districts, considering the environmental aspects and human health while assessing 26 water quality parameters like color, odour,taste, turbidity, $\mathrm{pH}$, total hardness, iron, chloride, chlorine, fluoride, total dissolved solids, calcium, magnesium, copper ,manganese, sulphate, nitrate, phenolic compound, arsenic, cadmium, lead, zinc, chromium, alkalinity and coliform bacteria etc. and also provide feasible solution of sustainable availability of water.

Geospatial water quality and quantity model help to find out the spatio-temporal analysis of contamination and particles movement in the watersheds. Modern geo statistical simulation algorithms can produce multiple subsurface realizations that are in agreement with the conceptual geological models. The quality modeling and monitoring will help in providing portable surface and ground waters. Evapotranspiration and percolation can be accessed through spatial model tool like Soil and Water Assessment Tools (SWAT) and used for simulating the impact of land cover practices on the peizometer wells in the area.Few hydro-geological characteristics like hydraulic conductivity, transmissivity, storage parameters and effective porosity will be quantified with observed lithology and geology data. Once the water quality study is completed the geospatial mapping of water quality and stress index will be performed using GIS environment. Water quality vulnerability index will provide knowledge of regional disparities to any water user for proposing any technology and policies. Several other solution methods are available to solve the solute transport equation and they can be categorized as particle-based methods, finite-difference methods and a total-variationdiminishing (TVD) method. Briefly, the particlebased methods, Method of Characteristics (MOC), Modified Method of Characteristics (MMOC) and Hybrid Method of Characteristics (HMOC), solve the advection term using conventional particle tracking based on a mixed Eulerian-Lagrangian approach and solve the dispersion and source/sink 
mixing terms using finite difference (Zheng and Wang, 1999; Zheng, 1999). Regional level quantifications of water quality for preparing a water resource action plan at watershed level, to reach sufficient quality water at urban cluster and surrounding rural areas. A geospatial model is prepared for assessing aquifer and surface water dynamics for potential sites of surface water percolation (infiltration) in soil profiles and ground water recharge for local livelihood. It will assist in finding out the source and keep track of contamination through geospatial tools. An action plan is prepared for aquifer augmentation and sustainability of life and livelihoods of inhabitants of the studied area. The model which will be developed in this study can be replicated in other parts of the country those having same topography.

\section{Conclusion}

The overall outcome of the present study is expected to be fruitful for tackling the local environment degradation of water aiming at better human health and improved agricultural demand nearby urban cluster. The present study not only impart, the mapping of water sources, it will also provide the scientific solution to avail a potable per capita water demand in urban as well as rural area.l

\section{Acknowledgement}

Authors are thankful to Water Technology Initiative Division, Department of science and technology (Government of India) for financial support.

\section{References}

Asheesh and Mohamed. 2003. Allocating the Gaps of Shared Water Resources (The Scarcity Index) Case Study Palestine Israel. IGME, 797-805.
Brown, A. and Matlock, M. D. 2011. A review of Water Scarcity Indices and methodologies. The Sustainability Consortium. White Paper, 106.

Carr, G. M. and Neary, J. P. 2010. Water Quality for Ecosystem and Human Health. United Nations Environment Programme Global Environment Monitoring, 2nd Edition. In: Ross, Nancy et al, Clearing the Waters: A Focus on water Quality solutions. Unites Nations Environment Programme, UNON, Publishing Services Section, Kenya.

Chiang, W. H. and Kinzelbach, W. 1998. An Advective Transport Model For Calculating .3D Paths. PMPATH 98 is designed for using with (PMWIN Version 4.0) and MODFLOW.

CPCB, 2009. Ganga Water Quality Trend, Monitoring of Indian Aquatic Resources, Central Pollution Control Board, Ministry of Environment and Forests Series: MINARS/31/2009-2010. (Last accessed May 2015)

DST, 2015. http://dst.gov.in/scientific-programme/ Water_Challenged_Sites_for Research Based_Solution.pdf (last accessed May 2015)

GALDIT

method http://www.aprh.pt/celtico/PAPERS/ts3p25_presentation

Linde, N., Renard, P., Mukerji, T., Caers, J. 2015. Geological realism in hydrogeological and geophysical inverse modeling: A review. Advances in Water Resources, 86: 86-101.

Zheng, C. 1999. MT3D: A modular three-dimensional transport model forsimulation of advection, dispersion and chemical reactions of contaminants in groundwater systems, 199

Zheng, C. and Wang PP. 1999. MT3DMS: A modular threedimensional multispeciesmodel for simulation of advection, dispersion and chemicalreactions of contaminants in groundwater systems: documentationand user's guide. Vicksburg, MS: SERDP-99-1, US Army EngineerResearch and Development Center; 